\title{
Airglow observations over the equatorial ionization anomaly zone in Taiwan
}

\author{
J. Y. Liu ${ }^{1,2}$, P. K. Rajesh ${ }^{1}$, I. T. Lee ${ }^{1}$, and T. C. Chow ${ }^{3}$ \\ ${ }^{1}$ Institute of Space Science, National Central University, Chung-Li 32001, Taiwan \\ ${ }^{2}$ Center for Space and Remote Sensing Research, National Central University, Chung-Li 32001, Taiwan \\ ${ }^{3}$ Department of Physics, National Sun Yat Sen University, Kaohsiung 80424, Taiwan
}

Received: 14 September 2010 - Revised: 1 March 2011 - Accepted: 18 April 2011 - Published: 5 May 2011

\begin{abstract}
Airglow imaging at mid-latitude stations often show intensity modulations associated with medium scale travelling ionospheric disturbances (MSTID), while those carried out near the equatorial regions reveal depletions caused by equatorial plasma bubbles (EPB). Two all sky cameras are used to observe plasma depletions in the $630.0 \mathrm{~nm}$ emission over the equatorial ionization anomaly (EIA) region, Taiwan $\left(23^{\circ} \mathrm{N}, 121^{\circ} \mathrm{E} ; 13.5^{\circ} \mathrm{N}\right.$ Magnetic) during 1998-2002 and 2006-2007. The results show EPB and MSTID depletions in different solar activity conditions. Several new features of the EPB depletions such as bifurcation, secondary structure on the walls, westward tilt, etc., are discussed in this paper. Evidence of tilted depletions with secondary structures developing on the eastern wall that later evolve to appear as bifurcations, are presented for the first time. Moreover, detail investigations are carried out using International Reference Ionosphere (IRI) model as well as the electron density from Ionosonde and Global Positioning System (GPS) Occultation Experiment (GOX) onboard FORMOSAT-3/COSMIC satellite, to understand the conditions that favor the propagation of MSTID to the latitude of Taiwan.
\end{abstract}

Keywords. Ionosphere (Ionosphere-atmosphere interactions; Ionospheric disturbances; Ionospheric irregularities)

\section{Introduction}

All-sky imaging of airglow depletions has been widely employed to study ionospheric irregularities with the pioneering work of Weber et al. (1978), who made airborne measurements of oxygen $630.0 \mathrm{~nm}$ emission. Such airglow investigations are mostly used in the study of equatorial plasma

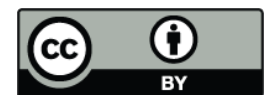

Correspondence to: J. Y. Liu (jyliu@jupiter.ss.ncu.edu.tw) bubbles (EPBs) associated with Equatorial Spread-F (ESF) irregularities (Mendillo and Baumgardner, 1982; Sahai et al., 2000; Fagundes et al., 1999; Taylor et al., 1997; Sinha et al., 2001; Kelley et al., 2002; Makela et al., 2004; Mendillo et al., 2005; Rajesh et al., 2007). The irregularities are generated at the magnetic equator when suitable conditions exist at the F-region bottom-side in the post-sunset period, and manifest themselves as dark bands of intensity depletions in the airglow images taken from equatorial and low-latitude stations (Weber et al., 1978; Mendillo et al., 2005). The depletions are aligned along magnetic field lines, and usually drift eastward with the ambient plasma velocity (Mendillo and Baumgardner, 1982; Sinha et al., 2001; Martinis et al., 2003; Pimenta et al., 2003).

Observations at mid-latitude stations also show airglow depletions, which are caused by medium scale travelling ionospheric disturbances (MSTID) (Shiokawa et al., 2003). The characteristics of these depletions are different from those of EPBs, with the majority of the images taken from Northern Hemisphere showing northwest to southeast alignment and southwestward drift (Garcia et al., 2000; Shiokawa et al., 2003). Shiokawa et al. (2002) suggested an equatorward limit of about $\sim 18^{\circ} \mathrm{N}$ magnetic latitude for the southwestward propagation of the MSTIDs. However, Ogawa et al. (2009) reported an MSTID event that reach $10^{\circ} \mathrm{N}$ magnetic latitude, while Candido et al. (2008) observed MSTID depletions in the Southern Hemisphere from a station at $13.2^{\circ} \mathrm{S}$ (magnetic).

Taiwan, located right under the northern crest of the equatorial ionization anomaly (EIA), is an ideal place to image airglow depletions, where one can see high altitude EPB depletions which often appear bifurcated. Such depletions are reported in the all sky observations over a low-latitude station in Taiwan, in 1999 (Chow et al., 2002). The depletions showed eastward drifts of about $115 \mathrm{~m} \mathrm{~s}^{-1}$ during 21:30 22:00 Local Time (LT) periods. The apex height of the depletions was estimated to be about $1500 \mathrm{~km}$, and their east-west

Published by Copernicus Publications on behalf of the European Geosciences Union. 


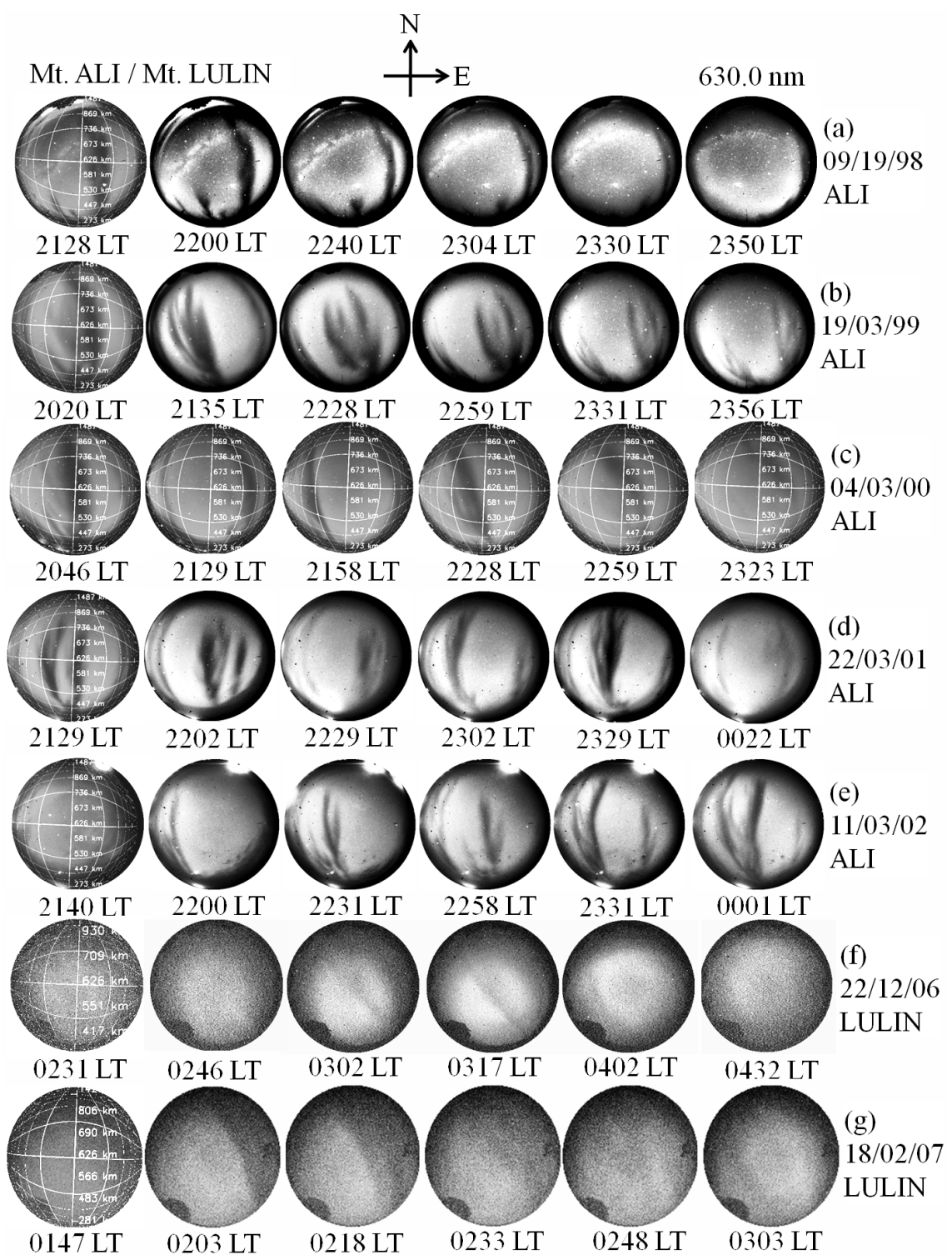

Fig. 1. Examples from the 630.0 nm images taken during 1998-2002 (a-e), and 2006-2007 (f-g), over Taiwan, with date (DD/MM/YY), and location on the right. Magnetic grid lines at every $2^{\circ}$ and the apex height at every 50th pixel from the image center are plotted on the first image of each panel and also for the all images on panel (c).

extension was about $290 \mathrm{~km}$. The recent all sky observations over Taiwan, however, show depletions with characteristics of the MSTIDs. This paper examines the EPB and MSTID depletions over the latitude of Taiwan, and discusses the conditions under which the equatorial and mid-latitude disturbances could be imaged over a low latitude station.

\section{Instrument}

Airglow images taken with two different all sky cameras are used in this study; the imaging system of Department of Physics, National Sun Yat Sen University (NSYSUPD all sky imager) (Chow et al., 2002), and the all sky imager developed at the Institute of Space Science, National Central University (NCUISS all sky imager). Both the systems use identical Nikon $8 \mathrm{~mm}, \mathrm{f} / 2.8$ fish eye lens with a field-of-view (FOV) of $180^{\circ}$. The fish eye lens maps a hemispherical area (of theoretically calculated diameter of about $3600 \mathrm{~km}$ at $250 \mathrm{~km}$ altitude) to a circular image of $23 \mathrm{~mm}$ diameter. Since this causes large compression at the edges of the image, the usable FOV is restricted to $150^{\circ}$ for practical calculations. The observations are made using a $630.0 \mathrm{~nm}$ interference filter of $1 \mathrm{~nm}$ bandwidth. The images are corrected for camera bias, dark noise, and background, and are presented so as to have the best possible contrast to enhance various features of 
Table 1. Minimum and maximum values of the width and velocity of EPB depletions under quiet and disturbed magnetic conditions on the days for which, calculations were possible during 1998-2002.

\begin{tabular}{lcccccc}
\hline \multirow{2}{*}{$\begin{array}{l}\text { Magnetic } \\
\text { activity }\end{array}$} & $\begin{array}{c}\text { Days } \\
\text { used }\end{array}$ & \multicolumn{2}{c}{ Width $(\mathrm{km})$} & & \multicolumn{2}{c}{ Velocity $\left(\mathrm{m} \mathrm{s}^{-1}\right)$} \\
\cline { 3 - 4 } \cline { 6 - 7 } & & Min & Max & & Min & Max \\
\hline Quiet & 9 & 30 & 305 & & 20 & 160 \\
Disturbed & 11 & 25 & 210 & & 10 & 170 \\
\hline
\end{tabular}

interest, and hence a visual comparison of the relative intensities in different images could be misleading.

\section{Observation}

Imaging observations using $630.0 \mathrm{~nm}$ were conducted from Mt. Ali $\left(23.5^{\circ} \mathrm{N}, 120.8^{\circ} \mathrm{E} ; 13.5^{\circ} \mathrm{N}\right.$ Magnetic, $\sim 2500 \mathrm{~m}$ above mean sea level), Taiwan, during 1997-2002 using the NSYSUPD all-sky imager and from Mt. Lulin $\left(23.47^{\circ} \mathrm{N}, 120.87^{\circ} \mathrm{E} ; 13.45^{\circ} \mathrm{N}\right.$ Magnetic, $2862 \mathrm{~m}$ above mean sea level), Taiwan, during 2006-2007 using the multiwavelength NCUISS all-sky camera. During the years 19972002, there were about 44 nights of observations with depletions. Out of these, about $40 \%(18 / 44)$, of the nights were magnetically disturbed ( $\mathrm{Kp}>3$ for three consecutive $3 \mathrm{~h}$ periods). The observations in 2006-2007, are limited to about 16 clear nights between August (2006) to July (2007), and out of these, depletions occurred on two occasions. Both the nights were magnetically quiet. No further useful data could be collected during 2007-2009 with most of the new moon period being cloudy, and also due to some technical problems with the imager for a short interval. The NCUISS all sky imager was later upgraded with a new CCD camera, and is currently making routine observations from Mt. Lulin since February 2010, depending on weather and moon phase.

Figure 1 gives selected examples of the images taken from 1998 till 2007. The first five rows (panels a-d), correspond to a period of increasing solar activity (1998-2002). Most of these observations are in the equinox months of FebruaryApril and September-November. The depletions in general are aligned along North-South $(\mathrm{N}-\mathrm{S})$ and drift eastwards with velocities in the range $60-170 \mathrm{~m} \mathrm{~s}^{-1}$ in the pre-midnight period. The east-west extension (width) was in the range $60-300 \mathrm{~km}$. The alignment and drift suggest their association with the field aligned EPB irregularities (Chow et al., 2002). Note that in 1997, there was only one night with depletions (not shown in Fig. 1). However, these depletions were limited to the Southern end of the FOV, indicating that the bubble did not rise to higher altitudes over the equator. Except for one occasion (panel a), the depletions in 1998 were also mostly seen within the Southern half of the FOV. The observations in 1999 and later years showed several in-
Table 2. Apex height and width of selected bifurcations.

\begin{tabular}{cc}
\hline Apex height $(\mathrm{km})$ & Width $(\mathrm{km})$ \\
\hline 425 & 265 \\
475 & 115 \\
400 & 145 \\
480 & 115 \\
450 & 230 \\
500 & 150 \\
440 & 150 \\
400 & 55 \\
470 & 120 \\
485 & 200 \\
520 & 120 \\
550 & 65
\end{tabular}

stances when depletions covered the entire N-S FOV. The drift, width and N-S coverage of depletions is different in different nights, and appeared to be independent of magnetic activity (Table 1).

One common characteristic of the depletions is bifurcation of their northern ends. Most of the depletions appear bifurcated from the time when they appear in the images, revealing Y-shaped or wishbone patterns (Mendillo and Tyler, 1983). The bifurcation is less structured in the images in 1997 and 1998, but often appears to be very complex in the other years, irrespective of magnetic activity. Table 2 gives the apex height and width of selected well defined bifurcations. It can be seen that the lowest apex height of the observed bifurcations is about $400 \mathrm{~km}$, and the minimum width of a bifurcated depletion is about $55 \mathrm{~km}$. In addition to the bifurcations, several depletions had branching or secondary structures developing over their walls. One such spectacular feature is imaged in the night of 3 March 1999 (panel b), where multiple structures that appear as striations emerge from the eastern wall of the depletion in the image at 20:20 LT. Secondary depletions are also seen over the western wall of the depletions in some of the nights (for example, the image at 20:46 LT on 4 March 2001, on the panel c), while the eastern wall appeared less structured.

Another important feature of the EPB depletions in Fig. 1 is the westward tilt, which can be seen pronounced in the images taken in the night of 4 March 2000 (see for example, the image at 22:28 LT on panel c). The depletion at 21:29 LT starts to gradually tilt westward. The tilt is uniform over all the altitudes above the equator (i.e., all the latitudes covered by the depletion within the FOV), until about 22:28 LT. At $22: 45 \mathrm{LT}$, a portion of the depletion above the apex height of about $625 \mathrm{~km}$ appears to have a greater tilt compared to the portion beneath it. This becomes more evident in the images at 22:59 LT and 23:23 LT. However, not all the depletions imaged in the same night reveal such severe westward 
tilt. Though the westward tilt is a common feature of depletions, such extreme behavior has not yet been reported. Further examples of EPB depletions given in panels (d) and (e) are observed in the years 2001 and 2002, respectively. While complex secondary structures on both the eastern and western edges of the two bifurcated branches of the depletion can be seen in the image at 21:29 LT in panel (d), the images at 23:31 LT and 00:01 LT on panel (e) reveals an eastward tilt of the top half of the depletions, opposite to what is seen in panel (c).

The last two rows (panels $\mathrm{f}$ and g), in Fig. 1 correspond to the images taken during August 2006 to July 2007, a period of minimum solar activity. Very faint dark bands are seen in some of the images on the two rows, especially at 02:31 LT, 03:02 LT, and 03:17 LT on panel (f), and during 01:47-02:18 LT on panel (g). The depletions are oriented along northwest to southeast and appear to be drifting in the southwest direction. This is in complete disagreement with the orientation and drift of those observed in the five years of imaging experience during 1998-2002 over Taiwan, and apparently suggests that these are not related to the ESF. On the other hand, such airglow structures have been reported to be associated with the southwestward propagating MSTIDs (Garcia et al., 2000; Shiokawa et al., 2003). The depletions in this case drifted with a velocity of $\sim 60 \mathrm{~m} \mathrm{~s}^{-1}$ (southwestward direction) and their width was about $60-70 \mathrm{~km}$. Again, these values in general agree with those in the statistical studies of Garcia et al. (2000) and Shiokawa et al. (2003). The observations reported here confirm that the MSTIDs, usually imaged at the mid-latitudes, could propagate farther equator ward to reach the latitudes of Taiwan.

\section{Discussion}

Generalized Rayleigh-Taylor instability is believed to be the mechanism of generation of ESF irregularities, which operates in presence of sharp plasma density gradients antiparallel to the gravity (Kelley, 1989, and references therein). The irregularities are generated at the bottom side of the Fregion, evolve to the topside involving non-linear processes, and the regions of depleted plasma (EPB) rise vertically to very high altitudes (Woodman and La Hoz, 1976; Chaturvedi and Ossakow, 1977). One of the basic requirements for the development of spread-F is the rapid uplifting of the F-layer to very high altitudes by the pre-reversal enhancement of zonal electric field in the post-sunset hours (Farley et al., 1970; Tsunoda and Ecklund, 2007). The evening vertical drift, or the pre-reversal electric field increases with solar flux (Abdu et al., 1983; Fejer et al., 1999), which could lead to greater rate of occurrence of ESF and EPB during the periods of higher solar activity (Sahai et al., 2000; Sobral et al., 2002). Growth rate for Perkins instability (Perkins, 1973), which is used to explain the generation of MSTID (Kelley and Fukao, 1991), is inversely proportional to ion-neutral collision frequency. When the solar activity is low, the smaller ion-neutral collision frequency could give a significantly higher growth rate for the Perkins instability (Kelley and Fukao, 1991), thus favoring more occurrence of MSTID than high solar activity period.

The observations described above depict the characteristics of airglow depletions in solar maximum and solar minimum over the EIA zone over Taiwan. The EPBs associated with the ESF are distributed along magnetic field lines as they grow non-linearly to the top-side at the equator to appear as depletions in airglow images (Weber et al., 1978; Mendillo et al., 2005). Chow et al. (2002) report that EPBs over Taiwan attain altitudes of $1500 \mathrm{~km}$ above the equator during the solar maximum year of 1999. The depletions reported here often cover the entire N-S of the FOV, where the apex altitude crosses over $2000 \mathrm{~km}$. The maximum latitude of the depletion depends upon the background ionospheric conditions at the equator and the flux tube integrated parameters that influence the development of ESF irregularities, causing the bubble to rise to higher altitudes, and then distribute to higher latitudes (Mendillo et al., 2005), often covering the EIA zone. The observations of EPB depletions over Taiwan in the solar maximum years of 1998-2002, and their absence in the solar minimum years of 2006-2007 (though the number of observations are less), indicate that suitable conditions for the evolution of bubbles are often met in the solar maximum.

The bifurcation of the poleward ends of the EPB depletions have been discussed in several previous investigations (Mendillo and Baumgardner, 1982; Rohrbaugh et al., 1989; Pimenta et al., 2001; Kelley et al., 2002). Depletions are shown to bifurcate when the ratio of the field line integrated conductivities inside and outside the bubble is less than 10 (McDonald et al., 1981; Zalesak et al., 1982; Anderson and Mendillo, 1983). Huang and Kelley (1996) suggested that the electric field within wider bubbles could be inhomogeneous, causing the upward moving charged particles to walk to two sides, resulting in bifurcation. The observations reported here show bifurcation of depletions having apex altitude of about $400 \mathrm{~km}$, with width as small as about $55 \mathrm{~km}$ (Table 2). In such cases, it can be speculated that the bifurcation starts at the early stages in the development of the bubble. However, there are several examples for the overhead evolution of bifurcation, which is probably not reported earlier. In such cases, the bifurcations develop from the structuring of the walls of the primary depletion. Thus, in addition to the conductivity ratio and the polarization electric field, the possible role of secondary instabilities in manifesting as bifurcation is discussed below.

Figure 2 displays an example of a sequence of images taken in the night of 1 October 2000, which gives evidence for the overhead development of secondary depletions on the eastern wall of an existing depletion. A small bulge is seen on the eastern wall of the depletion at 21:05 LT, and the subsequent images depict the growth of this structure. Another 


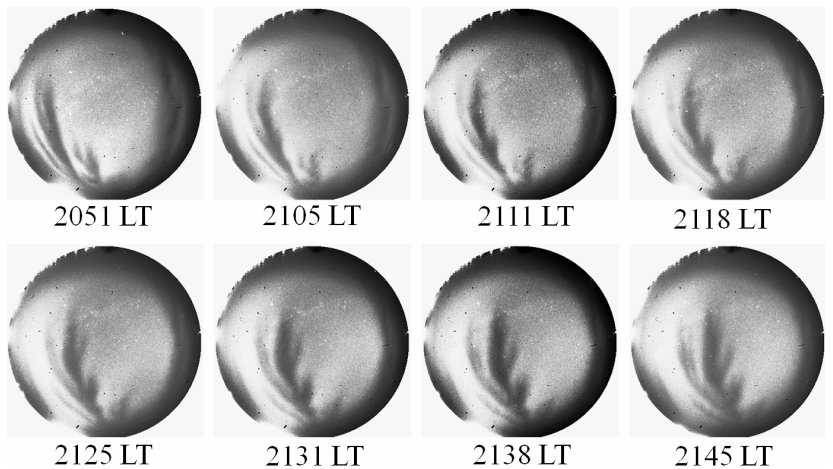

Fig. 2. Sequence of depletions taken in the night of 1 October 2000, from Mt. Alishan, showing overhead bifurcation. The orientation of the images is same as that in Fig. 1.

similar bulge also appears further northward, which is visible at 21:18 LT, and develops into a bifurcation structure by 21:25 LT. The apex altitudes where the bulges first appear are around 540 and $615 \mathrm{~km}$, respectively, and the corresponding width of the depletion is about $110 \mathrm{~km}$. At the time of the generation and development of these secondary depletions on the eastern wall, the primary depletion was drifting eastwards at a speed of $35-55 \mathrm{~m} \mathrm{~s}^{-1}$. Note that when the secondary structures start to grow on the eastern wall, the primary depletion appears well developed with a significant westward tilt. The secondary structure subsequently evolves to take the form of a bifurcated depletion (the images in the second row of Fig. 2). Another example for the development of bifurcation from the structuring of the eastern wall is illustrated in Fig. 3. The small bulge that appears around 20:54 LT, on the eastern wall of the depletion, which is near the western edge of the image, gradually evolves to a bifurcation (images in the second and third rows). Mendillo and Tyler (1983) had speculated that a secondary depletion developing in the steep gradients of the eastern wall of a westward tilted depletion could appear as bifurcation. The examples in Figs. 2 and 3 provide the experimental evidence for the bifurcations formed by the secondary structures that develop on the eastern wall of the primary depletion.

However, most of the previous observations had shown that it is the western wall of a depletion, which is much steeper where wind driven gradient-drift instability could produce secondary depletions (Mendillo and Baumgardner, 1982; Rohrbaugh et al., 1989; Kelley et al., 2002; Pimenta et al., 2003), and not the eastern wall. The observations analyzed in this study, on the other hand, show secondary structures on either wall of the depletions (Fig. 1), and the examples in Figs. 2 and 3 demonstrate the structuring on the eastern wall. The secondary depletion in Fig. 3 (that develops on the eastern wall of the primary depletion at 20:54 LT, and subsequently forms one of the pairs of the bifurcation), is itself susceptible to instability process and additional structuring is seen on its eastern wall from 21:56 LT. Figures 4

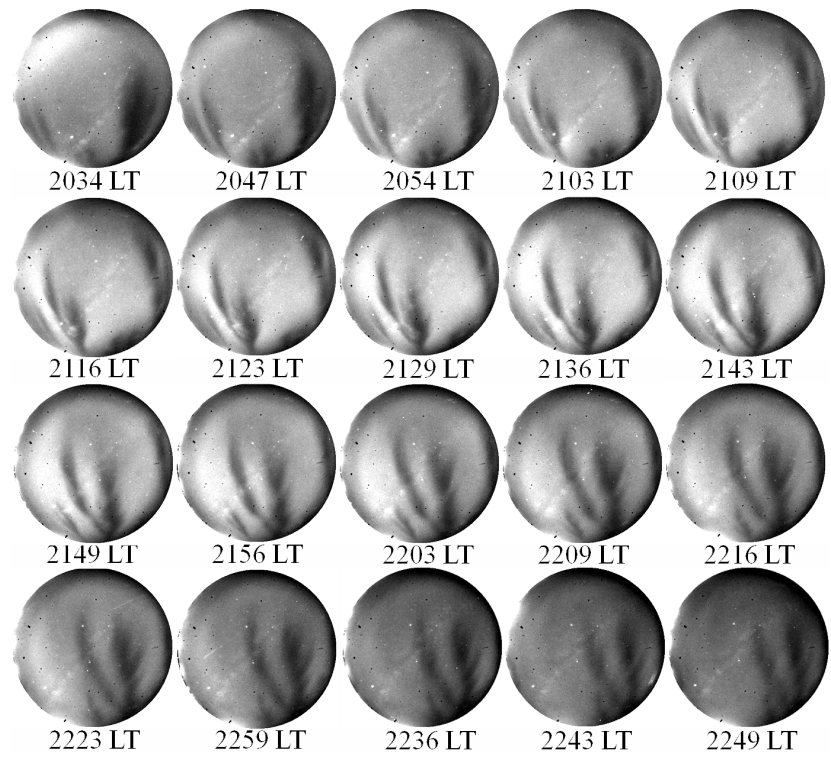

Fig. 3. Sequence of depletions taken in the night of 20 August 2001, from Mt. Alishan, demonstrating the evolution of bifurcation from the secondary structures developing on the eastern wall. The orientation of the images is same as that in Fig. 1.
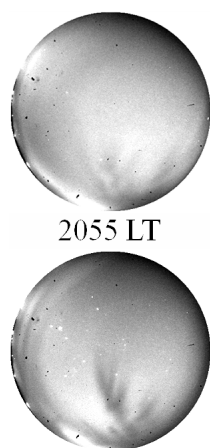

2122 LT

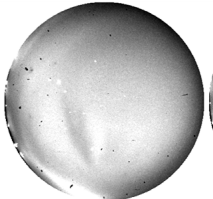

2102 LT

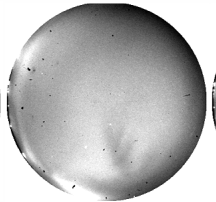

2129 LT
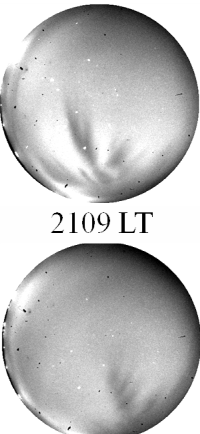

$2135 \mathrm{LT}$

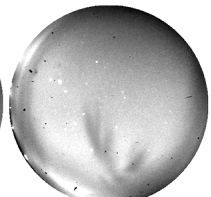

$2115 \mathrm{LT}$

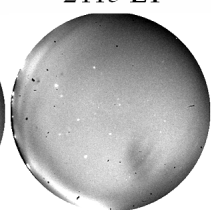

$2142 \mathrm{LT}$
Fig. 4. Sequence of depletions taken in the night of 22 February 2001, from Mt. Alishan, showing the structuring of the eastern wall. The orientation of the images is same as that in Fig. 1.

and 5 give further evidence for the structuring of the eastern wall. The development in Fig. 4 resembles that of the example in Fig. 2, while Fig. 5 reveals complex multiple structuring, again confirming that eastern wall could also become unstable.

Makela (2006) reported a case of secondary depletion on the eastern wall, when eastward drift of the depletion is reversed under magnetic disturbances. The modified background wind field and the westward drift favor stronger interaction and momentum transfer of the western wall, and steepens the gradients at the eastern wall, similar to that is proposed for the eastern wall under the typical eastward neutral wind and eastward plasma drift (Pimenta et al., 2003; 


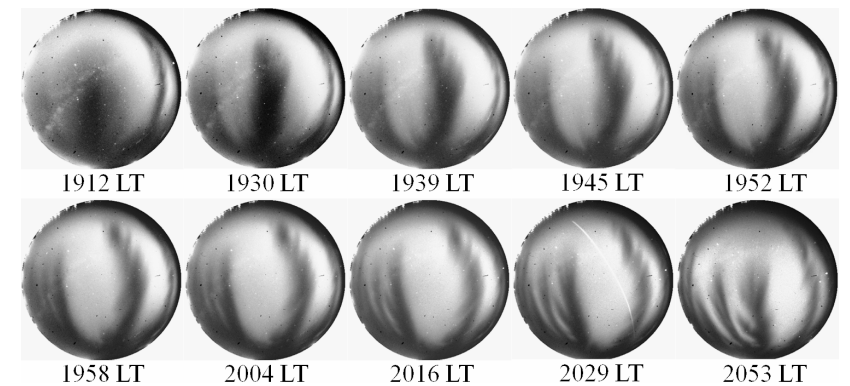

Fig. 5. Sequence of depletions taken in the night of 23 October 2000, from Mt. Alishan, revealing the unstable eastern wall with complex secondary patterns. The orientation of the images is same as that in Fig. 1.

Makela, 2006). Note that disturbed magnetic conditions were present in the night of 1 October 2000 (Fig. 2), as well as 23 October 2000 (Fig. 5). However, the depletions in both the cases drift eastward throughout the night and also at the time when secondary structures appear on the eastern wall. Thus, the results show that the eastern wall of depletion could become unstable even under the normal eastward drift. Moreover, quiet magnetic conditions exist in the nights of 20 August 2001 (Fig. 3) and 22 February 2001 (Fig. 4), when structuring of the eastern wall occurs with the depletions having the usual eastward drift. Thus, disturbed magnetic activity is not a necessary condition for the eastern wall to become unstable.

The observations thus show that either western or eastern wall of a depletion could be unstable to secondary instabilities. Note that, in most of the cases when the bifurcation was observed on the eastern wall, the primary depletion showed significant westward tilt, whereas bifurcation on the western wall appeared even for the cases where there is no tilt. However, there were two examples when the eastern wall developed secondary structures in the absence of tilt (Fig. 5), but in both the cases no bifurcation branches were developed. The results thus indicate that though the western wall is more likely to be unstable with the effect of eastward neutral wind, the bifurcation could appear on the eastern wall also when the primary depletion is tilted. Based on a local stability analysis, Zalesak et al. (1982) had proposed that when the depletion is tilted, secondary instability could operate along the western wall at low altitudes and eastern wall at high altitudes. Though no altitudinal preference was noted in the case of the secondary depletions on the western wall in the results discussed here, the apex altitude of the structures on the eastern wall was mostly above $500 \mathrm{~km}$.

The westward tilt of depletion with respect to the magnetic meridian has been reported by investigators (Mendillo and Baumgardner, 1982; Mendillo and Tyler, 1983; Rohrbaugh et al., 1989; Abalde et al., 2001; Kelley et al., 2003). It is explained based on shear in zonal plasma drift over the equator due to the altitude variation of integrated conductiv-

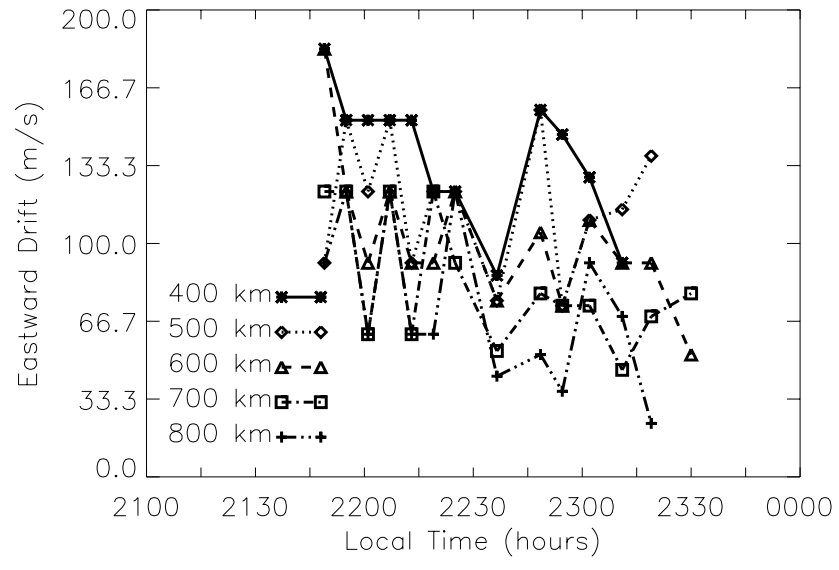

Fig. 6. Eastward drift velocity at different apex heights for the tilted depletion in the night of 4 March 2000 (panel c in Fig. 1).

ities (Zalesak et al., 1982), or the latitude variation of zonal winds (Anderson and Mendillo, 1983). The tilt of most of the depletions discussed here could be attributed to a similar mechanism. However, the anomalous tilts in some of the nights (for example, panel $\mathrm{c}$ of Fig. 1) indicate that the process involved could be very complicated. To further understand the westward tilted depletion in the night of 4 March 2000 , the eastward drift velocities estimated at different apex heights for the tilted depletion are plotted in Fig. 6. It can be seen that the depletion drifted faster at lower altitudes than at higher altitudes. Such differential velocities suggest shear in the zonal plasma drift at different altitudes above the equator. The difference in the drift velocities between the altitudes of 400 and $800 \mathrm{~km}$, in the interval 22:45-23:00 LT, is as large as about $100 \mathrm{~m} \mathrm{~s}^{-1}$. Under such shear flow, the depletion apparently bends at an apex altitude of about $625 \mathrm{~km}$.

The occurrence of MSTID, on the other hand, is found to be frequent during low solar activity years (Candido et al., 2008), when the conditions favor the Perkins instability, which is one suggested mechanism of generating MSTID's, with seeding by atmospheric gravity waves to provide sufficient growth rate (Kelley and Fukao, 1991; Garcia et al., 2000). However, several observations of MSTID occurrence have been reported in the solar maximum period of 19982000 over the mid-latitude region (Shiokawa et al., 2003). Ion-drag prevents the propagation of disturbances from highor mid-latitudes to low-latitudes (Tsugawa et al., 2003). Shiokawa et al. (2002) note that the ion-drag by the electron density at the EIA crest apparently limits the equator ward propagation of MSTID to $18^{\circ} \mathrm{N}$ Magnetic Latitude, while Ogawa et al. (2009) report MSTID depletions even reaching $10^{\circ} \mathrm{N}$ magnetic latitude in the solar minimum year of 2006. They attributed the amplitude of the perturbation and background ionospheric and thermospheric conditions for the equatorward propagation. Candido et al. (2008) observed MSTIDs over $13.2^{\circ} \mathrm{S}$ during low solar activity, and 


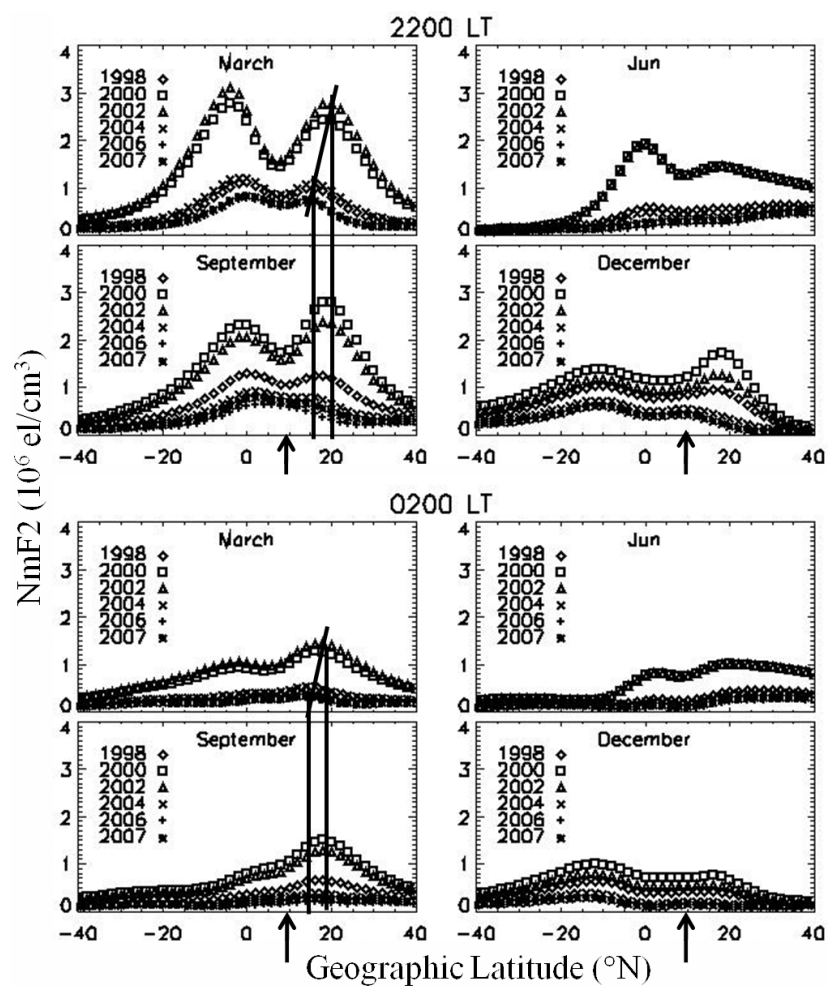

Fig. 7. The EIA crests over Taiwan longitude $\left(121^{\circ} \mathrm{E}\right)$ at $22: 00$ and 02:00 LT in different seasons during 1998-2007 as a function of latitude and $N m \mathrm{~F} 2$ using IRI07. The arrow denotes the magnetic equator.

suggested that plasma and neutral density variations could play important role. Recently, Makela et al. (2010) imaged MSTID events at latitudes near the magnetic equator during the deep solar minimum of 2007-2009. The NCUISS all sky imager is centered at magnetic latitude of about $13.5^{\circ} \mathrm{N}$, and the southward end of the observed MSTID propagate down to about $9^{\circ} \mathrm{N}$ magnetic.

To understand the observations of MSTID over Taiwan, extending beyond the EIA latitude, the location and strength of the crest during the years of the observations are examined. Figure 7 gives the latitudinal profiles of F-region peak electron density $(N m \mathrm{~F} 2)$ over Taiwan $\left(121^{\circ} \mathrm{E}\right)$, at $22: 00$ and 02:00 LT, respectively, in different seasons during the years of the imaging observations using the International Reference Ionosphere (IRI07) model (Bilitza, 2001). It can be seen from Fig. 7 that the northern EIA crest shows an equatorward shift with the decrease in solar activity. The crest locations move closer to the equator by about $5^{\circ}$ from solar maximum to solar minimum. Moreover, the MSTIDs are imaged over Taiwan during 02:00-04:00 LT, a period when electron density is very less. The above conditions might favor the MSTID propagation, exerting minimum ion-drag.

For further examination, the time constant for ion-drag $(\tau)$ is calculated for the period of MSTID observation in 2006,

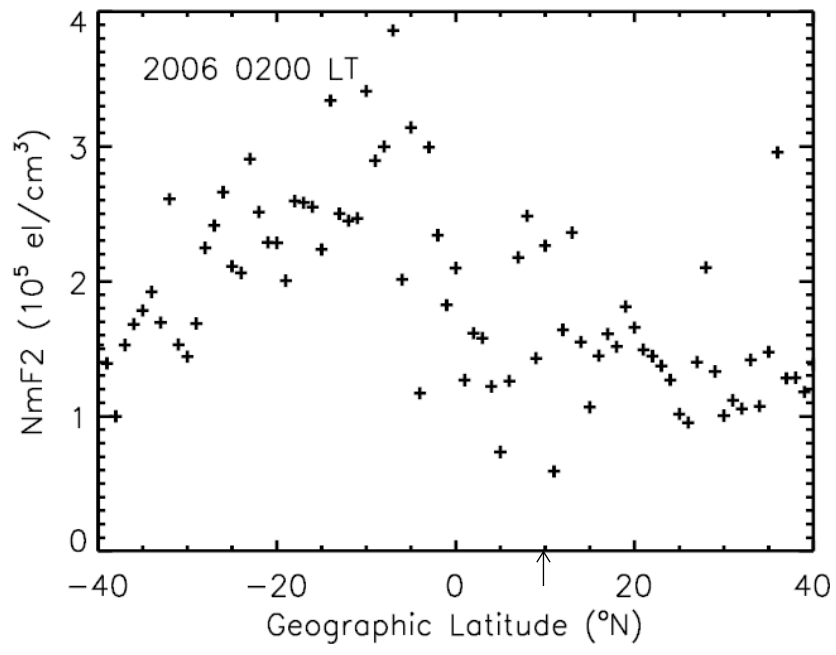

Fig. 8. GOX $N m \mathrm{~F} 2$ over Taiwan longitude $\left(121^{\circ} \mathrm{E}\right)$ at 02:00 LT in December 2006. The arrow denotes the magnetic equator.

as well as for the corresponding period in the solar maximum in 2000, following the method described by Lee et al. (2008). The IRI $N m$ F2 over the North EIA crest at 02:00 LT in December 2006 is about $1.4 \times 10^{11}$ electrons $\mathrm{m}^{-3}$, and the corresponding peak altitude is about $270 \mathrm{~km}$. The time constant in this case is about $1100 \min (2 \pi \tau)$. The neutral density and temperature are obtained from Mass Spectrometer Incoherent Scatter (MSISE-00) model (Hedin, 1991). Similarly, the $N m \mathrm{~F} 2$ at the EIA crest in the year 2000 is about $7.5 \times 10^{11}$ electrons $\mathrm{m}^{-3}$, and the time constant in this case is about $180 \mathrm{~min}$. The periodicities of MSTID range between 30 to $90 \mathrm{~min}$ and in some cases about $150 \mathrm{~min}$ (Garcia et al., 2000; Shiokawa et al., 2003; Ogawa et al., 2002), which is of the order of the time constant for ion-drag in 2000, while it is very different from that in 2006 . The wave propagation could be damped by ion-drag in 2000 when the periodicity is comparable to the time constant and such resistance is unlikely in 2006, enabling the equatorward propagation.

In addition to the time constant involved, the change of ion-drag in 2000 and 2006 is also examined. The ion-drag force is given by $N m_{\mathrm{i}} v_{\mathrm{in}}(U-V)$, where $N$ is the ion density, $m_{\mathrm{i}}$ is the mass of ion, $v_{\mathrm{in}}$ ion neutral collision frequency, $U$ and $V$ are, respectively, the velocities of neutral and ion (Kelley, 1991). Assuming that the velocities do not change, the ion-drag force at the time of MSTID observation in 2006 is about 16 times less than the corresponding value in the solar maximum year 2000. Also, note that while the change in ion-drag could offer minimum resistance to the equatorward propagation of MSTID in solar minimum, the growth rate of Perkins instability is significantly higher in solar minimum than the value in solar maximum (Kelley and Fukao, 1991). Thus, the MSTID events could be lesser in solar maximum. 
In the nighttime F-region, where quasi-neutral condition applies, the electron and ion densities are approximately identical, and hence the $N m \mathrm{~F} 2$ is used in the calculation of the ion-drag and time constant. For further verification, the $N m \mathrm{~F} 2$ from ionosonde measurements over Chung- $\mathrm{Li}\left(25^{\circ} \mathrm{N}\right.$, $\left.121^{\circ} \mathrm{E}\right)$, Taiwan, as well as that derived from Global Positioning System (GPS) Occultation Experiment (GOX) electron density profiles onboard FORMOSAT-3/COSMIC, are used to compare the ion-drag time constant calculated using IRI. The F-layer critical frequency $(f o F 2)$ in December 2006 when MSTID appear in the all sky imager is about $4.0 \mathrm{MHz}$, and it amounts to a time constant of about $800 \mathrm{~min}$. The corresponding time constant from IRI density is about $1800 \mathrm{~min}$. Though the difference is large, which is due to the difference in the model and measured densities, $800 \mathrm{~min}$ is still not comparable with the reported periodicity of MSTID. The GOX NmF2 in the night of December 2006, corresponding to a local time of 02:00 LT, over $121^{\circ} \mathrm{E}$ longitude is given in Fig. 8. It can be seen that the $N m \mathrm{~F} 2$ over $25^{\circ} \mathrm{N}$ is about $1.5 \times 10^{5}$ electrons $\mathrm{m}^{-3}$, and the time constant of ion-drag is about $1100 \mathrm{~min}$. The results thus indicate that the MSTID could appear over low-latitude stations in solar minimum years when the anomaly crests move closer to the equator and at the local times when the EIA is weak.

\section{Conclusion}

The MSTID and EPB can be observed in the EIA region during the solar minimum and maximum years, respectively. The EPB observations show that secondary depletions could be generated on either western or eastern wall or both of a depletion, and such structures could develop into bifurcations. The bifurcation appears on the eastern wall when the depletion is tilted westward, and the corresponding apex altitude is mostly above $500 \mathrm{~km}$. The MSTID results indicate that ion-drag could be one of the possible causes for the lowlatitude limit of their propagation, and the location as well as strength of the EIA crest play important role. Finally, we expect to observe remarkable EPB features in Taiwan during the maximum years of the solar cycle 24 .

Acknowledgements. The authors are thankful to the faculty and staff of the Graduate Institute of Astronomy and Astrophysics, National Central University, Taiwan, and also the staff at the Mt. Lulin Astronomical Observatory for providing all logistical support to conduct the experiment, and to the faculty and staff involved in the NSYSUPD all sky imager operation and data analysis during 1997-2002. The authors also thank the reviewers for their comments and suggestions that have helped to improve the presentation of the manuscript. This work is supported by National Science Council grants NSC98-2111-M-008-008-MY3 and NSC98-2116M-008-006-MY3, to National Central University, TAIWAN.

Topical Editor K. Kauristie thanks E. S. Miller and another anonymous referee for their help in evaluating this paper.

\section{References}

Abalde, J. R., Fagundes, P. R., Bittencourt, J. A., and Sahai, Y.: Observations of equatorial $\mathrm{F}$ region plasma bubbles using simultaneous OI $777.4 \mathrm{~nm}$ and OI $630.0 \mathrm{~nm}$ imaging: new results, J. Geophys. Res., 106, 30331-30336, 2001.

Abdu, M. A., Medeiros, R. T., Bittencourt, J. A., and Batista, I. S.: Vertical ionization drift velocities and range spread $F$ in the evening equatorial ionosphere, J. Geophys. Res., 88, 399-402, 1983.

Anderson, D. N. and Mendillo, M.: Ionospheric conditions affecting the evolution of equatorial plasma depletions, Geophys. Res. Lett., 10(7), 541-544, 1983.

Bilitza, D.: International Reference Ionosphere 2000, Radio Sci., 36, 261-275, 2001.

Candido, C. M. N., Pimenta, A. A., Bittencourt, J. A., and BeckerGuedes, F.: Statistical analysis of the occurrence of mediumscale traveling ionospheric disturbances over Brazilian low latitudes using OI $630.0 \mathrm{~nm}$ emission all-sky images, Geophys. Res. Lett., 35, L17105, doi:10.1029/2008GL035043, 2008.

Chaturvedi, P. K. and Ossakow, S. L.: Nonlinear theory of the collisional Rayleigh-Taylor instability in equatorial spread-F, Geophys. Res. Lett., 4, 558-560, 1977.

Chow, T. C., Chou, H., Yeh, H. C., Su, S. Y., and Lia, C. H.: Coincident observations of equatorial bubbles by ROCSAT-1 and a ground imager at southern Taiwan, Adv. Space Res., 30, 2569 2574, 2002.

Fagundes, P. R., Sahai, Y., Batista, I. S., Abdu, M. A., Bittencourt, J. A., and Takahashi, H.: Observations of day-to-day variability in precursor signatures to equatorial F-region plasma depletions, Ann. Geophys., 17, 1053-1063, doi:10.1007/s00585-999-1053x, 1999.

Farley, D. T., Balsley, B. B., Woodman, R. F., and McClure, J. P.: Equatorial spread-F, implications of VHF radar observations, J. Geophys. Res., 75, 7199-7216, 1970.

Fejer, B. G., Scherliess, L., and de Paula, E. R.: Effects of the vertical plasma drift velocity on the generation and evolution of equatorial spread F, J. Geophys. Res., 104, 19859-19869, 1999.

Garcia, F. J., Kelley, M. C., Makela, J. J., and Huang, C.-S.: Airglow observations of mesoscale low-velocity traveling ionospheric disturbances at midlatitudes, J. Geophys. Res., 105(A8), 18407-18415, 2000.

Hedin, A. E.: Extension of the MSIS thermosphere model into the middle and lower atmosphere, J. Geophys. Res., 96, 1159-1172, 1991.

Huang, C.-S. and Kelley, M. C.: Nonlinear evolution of equatorial spread $F 2$. Gravity wave seeding of Rayleigh-Taylor instability, J. Geophys. Res., 101(A1), 293-302, 1996.

Kelley, M. C.: The Earth's ionosphere: plasma physics and electrodynamics, International Geophys. Series, 43, Academic Press, 1989.

Kelley, M. and Fukao, S.: Turbulent Upwelling of the MidLatitude Ionosphere, 2. Theoretical Framework, J. Geophys. Res., 96(A3), 3747-3753, 1991.

Kelley, M. C., Makela, J. J., Ledvina, B. M., and Kintner, P. M.: Observations of equatorial spread-F from Haleakala, Hawaii, Geophys. Res. Lett., 29(20), 2003, doi:10.1029/2002GL015509, 2002.

Kelley, M. C., Makela, J. J., Paxton, L. J., Kamalabadi, F., Comberiate, J. M., and Kil, H.: The first coordinated ground- and space- 
based optical observations of equatorial plasma bubbles, Geophys. Res. Lett., 30, 1766, doi:10.1029/2003GL017301, 2003.

Lee, C. C., Liou, Y. A., Otsuka, Y., Chu, F. D., Yeh, T. K., Hoshinoo, K., and Matunaga, K.: Nighttime mediumscale travelling ionospheric disturbances detected by network GPS receivers in Taiwan, J. Geophys. Res. 113, A12316, doi:10.1029/2008JA013250, 2008.

Makela, J. J.: A review of imaging low-latitude ionospheric irregularity processes, J. Atmos. Solar-Terr. Phys., 68, 1441-1458, 2006.

Makela, J. J., Ledvina, B. M., Kelley, M. C., and Kintner, P. M.: Analysis of the seasonal variations of equatorial plasma bubble occurrence observed from Haleakala, Hawaii, Ann. Geophys., 22, 3109-3121, doi:10.5194/angeo-22-3109-2004, 2004

Makela, J. J., Miller, E. S., and Talaat, E. R.: Nighttime medium scale travelling ionospheric disturbances at low geomagnetic latitudes, Geophys. Res. Lett., 37, L24104, doi:10.1029/2010GL045922, 2010.

Martinis, C., Eccles, J. V., Baumgardner, J., Manzano, J., and Mendillo, M.: Latitude dependence of zonal plasma drifts obtained from dual-site airglow observations, J. Geophys. Res., 108(A3), 1129, doi:10.1029/2002JA009462, 2003.

McDonald, B. E., Ossakow, S. L., Zalesak, S. T., and Zabusky, N. J.: Scale sizes and lifetimes of $\mathrm{F}$ region plasma cloud striations as determined by the condition of marginal stability, J. Geophys. Res., 86(A7), 5775-5784, 1981.

Mendillo, M. and Baumgardner, J.: Airglow characteristics of equatorial plasma depletions, J. Geophys. Res., 87, 7641-7652, 1982.

Mendillo, M. and Tyler, A.: Geometry of depleted plasma regions in the equatorial ionosphere, J. Geophys. Res., 88, 5778-5782, 1983.

Mendillo, M., Zesta, E., Shodhan, S., Sultan, P. J., Doe, R., Sahai, Y., and Baumgardner, J.: Observations and modeling of the coupled latitude-altitude patterns of equatorial plasma depletions, J. Geophys. Res., 110, A09303, doi:10.1029/2005JA011157, 2005.

Ogawa, T., Balan, N., Otsuka, Y., Shiokawa, K., Ihara, C., Shimomai, T., and Saito, A.: Observations and modeling of $630 \mathrm{~nm}$ airglow and total electron content associated with traveling ionospheric disturbances over Shigaraki, Japan, Earth Planets Space, 54, 45-56, 2002.

Ogawa, T., Otsuka, Y., Shiokawa, K., Tsugawa, T., Saito, A., Hoshinoo, K., Matunaga, K., Kubota, M., and Ishii, M.: Mediumscale travelling ionospheirc disturbances and plasma bubbles observed by all-sky airglow imager at Yonaguni, Japan, Terr. Atmos. Ocean Sci., 20, 1, doi:10.3319/TAO.2007.12.06.02(F3C), 2009

Perkins, F.: Spread F and ionospheric currents, J. Geophys. Res., 78, 218-226, 1973.

Pimenta, A. A., Fagundes, P. R., Bittencourt, J. A., and Sahai, Y.: Relevant aspects of equatorial plasma bubbles under different solar activity conditions, Adv. Space Res., 27(6/7), 1213-1218, 2001 .
Pimenta, A. A., Fagundes, P. R., Sahai, Y., Bittencourt, J. A., and Abalde, J. R.: Equatorial F-region plasma depletion drifts: latitudinal and seasonal variations, Ann. Geophys., 21, 2315-2322, doi:10.5194/angeo-21-2315-2003, 2003.

Rajesh, P. K., Liu, J. Y., Sinha, H. S. S., Banerjee, S. B., Misra, R. N., Dutt, N., and Dadhania, M. B.: Observations of plasma depletions in $557.7 \mathrm{~nm}$ over Kavalur, J. Geophys. Res., 112 , A07307, doi:1029/2006JA012055, 2007.

Rohrbaugh, R. P., Hanson, W. B., Tinsley, B. A., Cragin, B. L., McClure, J. P., and Broadfoot, A. L.: Images of transequatorial bubbles based on field-aligned airglow observations from Haleakala in 1984-1986, J. Geophys. Res., 94(A6), 6763-6770, 1989.

Sahai, Y., Fagundes, P. R., and Bittencourt, J. A.: Transequatorial Fregion ionospheric plasma bubbles: solar cycle effects, J. Atmos. Solar-Terr. Phys., 62, 1377-1383, 2000.

Shiokawa, K., Otsuka, Y., Ejiri, M. K., Sahai, Y., Kadota, T., Ihara, C., Ogawa, T., Igarashi, K., Miyazaki, S., and Saito, A.: Imaging observations of the equatorward limit of midlatitude traveling ionospheric disturbances, Earth Planets Space, 54, 57-62, 2002.

Shiokawa, K., Ihara, C., Otsuka, Y., and Ogawa, T.: Statistical study of nighttime medium-scale traveling ionospheric disturbances using midlatitude airglow images, J. Geophys. Res., 108(A1) 1052, doi:10.1029/2002JA009491, 2003.

Sinha, H. S. S., Rajesh, P. K., Misra, R. N., and Dutt, N.: Multi-wavelength imaging observations of plasma depletions over Kavalur, India, Ann. Geophys., 19, 1119-1131, doi:10.5194/angeo-19-1119-2001, 2001.

Sobral, J. H. A., Abdu, M. A., Takahashi, H., Taylor, M. J., de Paula, E. R., Zamlutti, C. J., de Aquino, M. G., and Borba, G. L.: Ionospheric plasma bubble climatology over Brazil based on 22 years (1977-1988) of $630 \mathrm{~nm}$ airglow observations, J. Atmos. Solar-Terr. Phys., 64, 1517-1524, 2002.

Taylor, M. J., Eccles, J. V., Labelle, J., and Sobral, J. H. A.: Highresolution OI $(630 \mathrm{~nm})$ image measurements of F-region depletion drifts during the Guara campaign, Geophys. Res. Lett., 24, 1699-1702, 1997.

Tsugawa, T., Saito, A., Otsuka, Y., and Yamamoto, M.: Damping of large-scale traveling ionospheric disturbances detected with GPS networks during the geomagnetic storm, J. Geophys. Res., 108(A3), 1127, doi:10.1029/2002JA009433, 2003.

Tsunoda, R. T. and Ecklund, W. L.: On the post-sunset rise of the equatorial $\mathrm{F}$ layer and superposed upwellings and bubbles, Geophys. Res. Lett., 34, L04101, doi:10.1029/2006GL028832, 2007.

Weber, E. J., Buchau, J., Eather, R. H., and Mende, S. B.: Northsouth aligned equatorial depletions, J. Geophys. Res., 83, 712 716, 1978

Woodman R. F. and La Hoz, C.: Radar observations of F-region equatorial irregularities, J. Geophys. Res., 81, 5447-5466, 1976.

Zalesak, S. T., Ossakow, S. L., and Chaturvedi, P. K.: Nonlinear equatorial spread $\mathrm{F}$ : the effect of neutral winds and background Pederson conductivity, J. Geophys. Res., 87(A1), 151$166,1982$. 